Review

\title{
DNA methylation in genetic and sporadic forms of neurodegeneration: Lessons from Alzheimer's, related tauopathies and genetic tauopathies
}

\author{
Geraldine Zimmer-Bensch ${ }^{1,2 *}$ and Hans Zempel ${ }^{3,4 *}$
}

1 Functional Epigenetics in the Animal Model, Institute for Biology II, RWTH Aachen University, 52074 Aachen, Germany

2 Research Training Group 2416 MultiSenses-MultiScales, Institute for Biology II, RWTH Aachen University; 52074 Aachen, Germany

3 Institute of Human Genetics, Faculty of Medicine and University Hospital Cologne, University of Cologne; 50931 Cologne, Germany

4 Center for Molecular Medicine Cologne (CMMC), Faculty of Medicine and University Hospital Cologne, University of Cologne; 50931 Cologne, Germany

* Correspondence: zimmer@bio2.rwth-aachen.de; hzempel@uni-koeln.de

\begin{abstract}
Genetic and sporadic forms of tauopathies, the most prevalent of which is Alzheimer's Disease, are a scourge of the aging society, and in case of genetic forms, can also affect children and young adults. All tauopathies share ectopic expression, mislocalization, or aggregation of the microtubule associated protein TAU, encoded by the MAPT gene. As TAU is a neuronal protein widely expressed in the CNS, the overwhelming majority of tauopathies are neurological disorders. They are characterized by cognitive dysfunction often leading to dementia, and are frequently accompanied by movement abnormalities such as parkinsonism. Tauopathies can lead to severe neurological deficits and premature death. For some tauopathies there is a clear genetic cause and/ or an epigenetic contribution. However, for several others the disease etiology is unclear, with few tauopathies being environmentally triggered. Here we review current knowledge of tauopathies listing known genetic and important sporadic forms of this disease. Further, we discuss how DNA methylation as a major epigenetic mechanism emerges to be involved in the disease pathophysiology of Alzheimer's, and related genetic and non-genetic tauopathies. Finally, we debate the application of epigenetic signatures in peripheral blood samples as diagnostic tool and usage of epigenetic therapy strategies for these diseases.
\end{abstract}

Keywords: Alzheimer; TAU; MAPT; epigenetics; neurodegeneration; neurogenetic disease; DNA methylation

Introduction: Features of sporadic and genetic forms of Alzheimer's and other tauopathies

Background: Neurodegenerative Diseases (NDDs) are characterized by irreversible loss of neurons or neuronal functions. They involve any neuronal subtype or function. Peripheral nervous system diseases leading to loss of neuronal functionality, e.g. due to loss or dysfunction of Schwann-cells in Charcot-Marie-Tooth and loss of axonal tracts in the absence or presence of neurodegeneration are also considered neurodegenerative disease. However, the term NDD is often used to describe conditions of the central nervous system (CNS) that are associated with neuronal loss and brain atrophy. The overwhelming majority of NDD-patients suffers from Alzheimer Disease (AD). 
Clinics of AD: Clinically, AD is characterized by cognitive dysfunction leading to dementia. Dementia describes the loss of once acquired cognitive functions, but should be discriminated from age-associated decline in cognitive abilities and performance. Cognitive impairment (CI) in AD typically begins with subtle failure of memory that may not be recognized clinically, but rather being recognized by the affected patient. This very subtle $\mathrm{CI}$ eventually develops into the so-called "mild cognitive impairment" (MCI) stage, with poorly recognized, but detectable failure of memory. Not all patients affected by MCI progress to AD: Progression of MCI to full blown dementia occurs with a $60 \%$ chance over ten years, and can be predicted by combining clinical, imaging-based, and laboratory diagnosis [1]. In most cases, however, $\mathrm{CI} / \mathrm{MCI}$ becomes more severe and, eventually, incapacitating. Other common findings include confusion, poor judgment, language disturbance, visual complaints, agitation, withdrawal, and hallucinations. Occasionally, seizures, Parkinsonian features, increased muscle tone, myoclonus, incontinence, and mutism occur. Death usually results from accompanying inanition (meaning severe loss of body weight, including muscle mass and subcutaneous fat), but also simply due to malnutrition, and often due to pneumonia or other typical diseases of patients that are bed-ridden [1]. The typical clinical duration of the disease is $9-11$ years, but can last up to 25 years. Roughly $95 \%$ of all AD is late onset (LOAD; age $>60-65$ years) and about $5 \%$ is early onset (EOAD; age $<60-65$ years). The risk of Alzheimer's is $60-80 \%$ dependent on heritable factors (see also current reviews [2] [3].

Pathomechanisms of $A D$ - a role of $A \beta$ and TAU in disease progression (Neuroanatomics, Clinics and Imaging Level): In AD, extracellular deposition of plaques composed of the Amyloid-beta $(\mathrm{A} \beta)$ protein, and intracellular aggregation of the protein TAU, are pathognomic of the disease. At autopsy, AD presents with diffuse extracellular and neuritic amyloid- $\beta(A \beta)$ plaques and intracellular neurofibrillary tangles and neuropil threads of hyperphosphorylated TAU, along with extensive neurodegeneration [4]. Leading hypotheses have postulated that these two hallmark proteins, $A \beta$ and TAU, either alone or in combination, are causative agents in disease etiology and progression, while local or global decrease in glucose consumption, observable at late stages, is rather considered as a downstream consequence of disease [5]. Aberrant production of A $\beta$, a 37-43 amino acid long peptide cleaved out of the Amyloid-Precursor-Protein (APP) by a.o. a complex composed of PSEN1/PSEN2, and A $\beta$ deposition in the form of amyloid plaques occur 20-30 years before the onset of CI. This is commonly placed as the upstream event in disease, but this amyloid hypothesis is heavily debated for 30 years [6,7]. In genetic forms of $\mathrm{AD}$, which usually manifest as EOAD, all known disease-causing mutations (namely APP, PSEN1, PSEN2, s. below and table 1) lead to an increase or aberration of $A \beta$ production. Yet, in mouse and cell culture models of $A D$, even dramatic exposure or overproduction of $A \beta$ is without significant effect, if the TAU protein is knockedout (or otherwise suppressed). This clearly hints towards TAU and proper cellular TAU distribution as an essential executor in mediating neurodegeneration and cognitive dysfunction [8-11]. Also, $A \beta$ deposition may be upstream of disease in $\mathrm{AD}$, but does not correlate with $\mathrm{CI}$. The histopathological hallmark of AD that correlates best with clinical symptoms and synapse loss, and in particular with $\mathrm{CI}$, is the progressive accumulation and aggregation of the microtubule associated 
protein (MAP) TAU, encoded by the MAPT-Gene. Disease progression from MCI to full blown $\mathrm{AD}$ as well as functional and structural brain deterioration is more closely related to, and can be predicted by (PET-) imaging based on TAU [12-14]. The appearance of TAU in specific cognitive networks leads to domain-specific cognitive impairments [15]. On a population basis, a stereotypical progression derived from histopathological stainings at autopsy, formalized via the Braak stageing system, exhibits a cortical spreading of TAU aggregates. The first appearance of TAU tangles is in the transentorhinal cortex. Tangles subsequently spread throughout the medial and basal temporal lobes, then into neocortical associative regions and finally into the unimodal sensory and motor cortex $[16,17]$. While this certainly holds true on a population basis, advances in PETimaging improved longitudinal clinical studies, and artificial intelligence (AI)based data interpretation have very recently allowed to better correlate the clinical symptoms in AD with structural and TAU-based brain abnormalities. These new data have revealed four different subtypes of $\mathrm{AD}$, that can now be described not only clinically, but in close correlation also using TAU-based PET-imaging [18]. While $A \beta$ deposition may be a far-reaching upstream trigger or indicator of disease onset, it is now fairly clear from a clinical, anatomical and imaging-based perspective that aberrant deposition and other changes in TAU are the main driver of $\mathrm{AD}$ pathology and consequent $\mathrm{CI}$.

Pathomechanisms of AD and related tauopathies - a role of TAU in neuronal dysfunction on a cellular \& molecular level: What are the molecular and cellular functions of TAU, and how are they impaired in disease? The protein TAU (UniProt: P10636, with isoform F being the largest isoform in the human CNS with 441 residues) is a microtubule-associated protein (MAP). MAPs are proteins that bind to assembled microtubules, and can promote the assembly of tubulin dimers into microtubules. TAU expression is upregulated during neuronal differentiation together with tubulin [19]. In normally matured healthy neurons in the Central Nervous System (CNS), TAU is predominantly present in neuronal axons and only very little evident in dendrites. There are several mechanisms discussed that enable the strong axonal targeting of TAU (for review see [11]). Human TAU is encoded on chromosome 17q21 [20], and the human CNS comprises six major alternatively spliced isoforms, with different isoform ratios depending on the developmental stage, cell type, and brain region [21,22]. A balanced isoform expression and epigenetic regulation of the isoforms may be crucial for both sporadic and genetic TAU-related diseases. Mutations in intronic $M A P T$ regions that lead to altered isoform expression of TAU, but not overall protein amount or the amino acid sequence, are sufficient to cause FTD-TAU reminiscent of AD and PSP [23,24]. Not only maintenance of the isoform ratio/distribution, but also the intracellular axodendritic distribution of TAU, i.e. successful axonal targeting, is essential to avoid neuronal dysfunction. In virtually all tauopathies, TAU protein is mislocalized and/or ectopically expressed, with mislocalization of TAU protein („,TAU missorting“) being the earliest sign of disease progression (for review see [25]). The individual TAU isoforms display differential sorting and expression patterns $[26,27]$. TAU missorting to dendrites and spines is associated with synaptic dysfunction, loss of microtubules and mitochondria, all of which are the first signs of neurodegeneration in AD. Also, missorting of TAU into the somatodendritic compartment occurs prior to the appearance of TAU aggregation and hyperphosphorylation in AD. It is thus clear 
that elucidating the molecular and cellular regulation of TAU is crucial to unravel the pathomechanism of $\mathrm{AD}$. The epigenetic mechanisms regulating intracellular and splice-isoform distribution are unresolved, but may be essential to elucidating key components of TAU driven toxicity in $\mathrm{AD}$ and related tauopathies: Sorting mechanisms are in part RNA-based, and epigenetic regulation of splicing is likely [11] (Zempel 2019).

The role of TAU as a driver of neuronal dysfunction becomes even clearer when we look beyond AD: Aberrant deposition of TAU in the somatodendritic compartment is a common feature of numerous neurodegenerative disorders known as tauopathies [25]. The formation of neurofibrillary tangles (NFTs), neuropil threads including hyperphosphorylated TAU protein, is the histopathological hallmark of tauopathies. This holds true not only for AD, but also for Frontotemporal Dementia (FTD) and variants thereof, such as Pick's Disease (PiD), Corticobasal Degeneration (CBD), Progressive Supranuclear Palsy (PSP), as well as other common (Parkinson Disease (PD), Traumatic Brain Injury (TBI)) and rare genetic diseases [28-31] (see also table 1 for a list of genetic, epigenetic, primary and putative secondary tauopathies).

Clinics and classification of taupathies: Besides AD, what are tauopathies? The spectrum of tauopathy encompasses a rather heterogenous group of NDDs characterized by neural or glial deposition of the protein TAU. Clinically they can present as cognitive syndromes, movement disorders, motor neuron disease, either with isolated disease manifestation or in various combinations [32], based on the vulnerable anatomical structures being affected by the pathological TAU protein accumulations. The heterogeneity in clinical presentation, genetic background, and underlying pathology make it difficult to classify and clinically approach tauopathy. Traditionally, tauopathies are classified as i) primary tauopathies, with TAU being either the predominant or the causative pathology, and ii) secondary tauopathies, where TAU pathology is either secondary to or appears in combination with other brain pathologies or insults (see below). Other classifications are e.g. the syndromic classification by Höglinger et al., that separates Cognitive Syndromes (e.g. behavioral variant of frontotemporaldementia (bvFTD), non-fluent agrammatic variant of primary progressive aphasia (nfavPPA), semantic variant of primary-progressive aphasia (svPPA), and amnestic syndrome of hippocampal type (AS)) from Motor Syndromes (e.g. Richardson syndrome (RS), Parkinson syndrome (PS), Corticobasal Syndrome (CBS), primary gait freezing (PGF), Cerebellar Syndrome (CS), and primary lateral sclerosis (PLS)). However, there is often overlap within the same disease etiology. Many primary tauopathies show aggregation or pathology only of 3-repeat (3R) or 4-repeat (4R) TAU isoforms, while most secondary tauopathies present with aggregation of all isoforms ( $3 R+4 R /$ mixed). Thus, tauopathies can also be classified into $3 R$, $4 R$ or mixed tauopathies. As the same genetic mutation in case of genetic forms of tauopathies, or different secondary tauopathies can disply similar disease manifestations, we here roughly reclassify tauopathies as either clearly genetic or epigenetic, idiopathic/sporadic, secondary/existing copathology, and (likely) environmental (for a list of tauopathies see table 1). 
Established genetic mechanisms of AD and tauopathies: For autosomaldominant inheritable forms of early onset AD, mutations in the genes APP, PSEN1 and PSEN2 coding for the amyloid-precursor-protein, presenelin-1 and presenelin-2, respectively, are causative for the disease. Homozygote carriers of the $\varepsilon 4$ allele of the apolipoprotein E, encoded by APOE(4), have a $\sim 15$-fold increased risk to be affected by early or late onset AD. Heterozygote carriers still have a 3-fold higher risk, but the overall risk is below 35\% and 20\%, respectively, while the Eta2 allele is clearly protective. In the last 10 years, mainly GWAS but also genome studies have revealed more than 20 (and possibly up to 75 according to recent preprints) risk loci/genes, that modulate disease risk. While the odds ratio for $A P O E(2)$ and $A P O E(4)$ for disease risk ranges from 0.56 to 14.49 , the odds ratio for other genes lies between 0.68 (PLCG2) and 2.08 (CD2AP). Of note, loci in the vicinity of $M A P T$ is associated with a reduced odds ratio for $\mathrm{AD}(0.73$ or 0.94$)$, indicating that $M A P T$ can also modify the risk for $\mathrm{AD}$ (for a full list of current risk genes and odds ratios we refer to other review articles [33-35]. 
Table 2. Exemplary list of tauopathies with (epi)genetic etiologies or risk factors [28,36-38].

\begin{tabular}{|c|c|c|c|}
\hline Disease entity & Clinic description/overview & Etiology & $\begin{array}{l}\text { Secondary to or } \\
\text { coexisting with }\end{array}$ \\
\hline $\begin{array}{c}\text { Familial FTLD-TAU } \\
\text { due to coding mutations in } \\
M A P T\end{array}$ & $\begin{array}{l}\text { Very heterogenous group of aging } \\
\text { associated tauopathies, which comprise } \\
\text { a.o. formerly FTDP17 }(t) \text { and patients } \\
\text { diagnosed with PSP }\end{array}$ & Genetic: $M A P T$ & 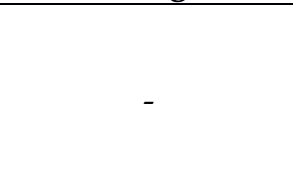 \\
\hline Vacuolar tauopathy & $\begin{array}{l}\text { FTLD-like syndrome due to defective } \\
\text { TAU disaggregation }\end{array}$ & Genetic: VCP [39] & - \\
\hline $\begin{array}{l}\text { Other forms of FTLD-TAU (like) } \\
\text { tauopathies }\end{array}$ & $\begin{array}{l}\text { Heterogenous group of aging associated } \\
\text { tauopathies, like CBD, PiD, GGT, AGD, } \\
\text { PART, ARTAG, most of which are further } \\
\text { subclassified }\end{array}$ & $\begin{array}{l}\text { Mostly sporadic, } \\
\text { (epi)genetic causes } \\
\text { unclear [28] }\end{array}$ & - \\
\hline $\begin{array}{l}\text { Progressive supranuclear palsy } \\
\text { (PSP) }\end{array}$ & $\begin{array}{l}\text { Rare neurodegenerative disorder, but a } \\
\text { common atypical Parkinson syndrome } \\
\text { with cognitive, motor, behavior and } \\
\text { language abnormalities, often diagnosed } \\
\text { as AD }\end{array}$ & $\begin{array}{c}\text { Epigenetic: } \\
\text { Hypomethylation of } \\
\text { MAPT [41] } \\
\text { Genetic: MAPT } \\
\text { Sporadic: GWAS with } \\
\text { loci close to MAPT, } \\
\text { STX6, EIF2AK3, MOBP, } \\
\text { DUSP, SLCO1A2, } \\
\text { RUNX2, a.o. [40] }\end{array}$ & 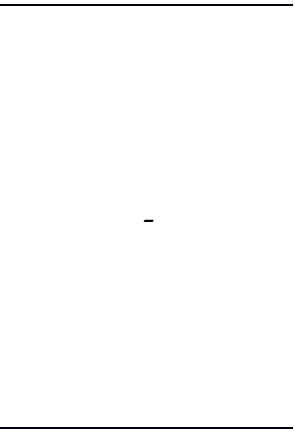 \\
\hline PSP look-alike syndromes & Clinically similar to PSP, rare & $\begin{array}{c}\text { Genetic: LRRK2, DCTN1, } \\
\text { BSN }\end{array}$ & unclear \\
\hline Familial Alzheimer Disease & $\begin{array}{c}\text { Age of Onset usually between } 40 \text { and } 70 \\
\text { years, fast progression }\end{array}$ & $\begin{array}{l}\text { Genetic: APP, PSEN1, } \\
\text { PSEN2, up to } 75 \text { risk } \\
\text { modifying genes } \\
\end{array}$ & $\begin{array}{l}\text { Amyloid- } \\
\text { pathology }\end{array}$ \\
\hline Familial Parkinson Disease & $\begin{array}{c}\text { Various group of familial Parkinson } \\
\text { Syndromes } \\
\end{array}$ & $\begin{array}{l}\text { Genetic: } S N C A, P R K N \text {, } \\
\text { LRRK2, other }\end{array}$ & $\begin{array}{c}\text { alpha-Synuclein } \\
\text { deposits }\end{array}$ \\
\hline Familial FTLD-ALS Syndromes & $\begin{array}{l}\text { Syndromes with manifestations ranging } \\
\text { from pure ALS to pure FTLD or } \\
\text { overlapping phenotypes }\end{array}$ & $\begin{array}{c}\text { Genetic: GRN, } \\
\text { C9ORF72, TARDBP, } \\
\text { other }\end{array}$ & $\begin{array}{c}\text { Deposits of } \\
\text { dipeptide repeats, } \\
\text { RNA inclusions, } \\
\text { TDP-43 } \\
\end{array}$ \\
\hline $\begin{array}{l}\text { Hereditary cerebral amyloid } \\
\text { angiopathy }\end{array}$ & $\begin{array}{l}\text { Familial forms of dementia (fam. British } \\
\text { and fam. Danish dementia }\end{array}$ & Genetic: ITM2B & $\begin{array}{l}\text { Amyloid- } \\
\text { pathology }\end{array}$ \\
\hline Niemann Pick Disease Type C & $\begin{array}{l}\text { Lysosomal storage disease with } \\
\text { hepatosplenomegaly, progressive } \\
\text { dementia and premature death ranging } \\
\text { from infancy to late adulthood }\end{array}$ & Genetic: NPC1, NPC2 & $\begin{array}{l}\text { Cholesterol } \\
\text { accumulations }\end{array}$ \\
\hline Kufs Disease & $\begin{array}{l}\text { A neurodegenerative lysosomal storage } \\
\text { disease / neuronal ceroid lipofuscinosis }\end{array}$ & $\begin{array}{l}\text { Genetic: CLN6 (PPT1, } \\
\text { DNAJC5, CTSF) }\end{array}$ & $\begin{array}{c}\text { Lipofuscin } \\
\text { accumulations }\end{array}$ \\
\hline Christianson Syndrome & $\begin{array}{l}\text { X-linked mental retardation syndrome } \\
\text { with microcephaly, muscle hypotonia, } \\
\text { movement disorder and epilepsy }\end{array}$ & Genetic: SLC9A6 & - \\
\hline $\begin{array}{l}\text { Mental Retardation, } X \text {-linked, } \\
\text { syndromic, Hedera type }\end{array}$ & $\begin{array}{l}\text { X-linked mental retardation syndrome } \\
\text { with global developmental delay, } \\
\text { parkinsonism, spasticity, and progressive } \\
\text { neurodegeneration }\end{array}$ & Genetic: $A T P 6 A P 2$ & $\begin{array}{l}\text { SQSTM1 } \\
\text { depositions }\end{array}$ \\
\hline $\begin{array}{l}\text { (Infantile) Sialic Acid Storage } \\
\text { Disease }\end{array}$ & $\begin{array}{l}\text { NDD with lysosomal dysfunction } \\
\text { presenting in infancy in its severe form }\end{array}$ & Genetic: SLC17A5 & - \\
\hline
\end{tabular}


or in adulthood with progressive brain atrophy.

Genetic forms of AD and related tauopathies, as well as the histopathology and imaging-based findings have elucidated possible connections and allowed initial mapping of cellular components and pathways involved. Still, genetic and signaling-based mechanisms alone can by far not exhaustively describe the pathomechanisms both of genetic and sporadic forms of neurodegeneration, in particular of $\mathrm{AD}$ and related pathology. Epigenetic mechanisms likely bridge the gaps in current knowledge of tauopathy disease mechanisms, and might provide mechanistic basis for environmental triggers.

\section{The epigenetic toolkit}

The epigenetic toolkit involves histone variants and modifications, alterations in nucleosome positioning, DNA methylation, and non-coding RNAs. As enormous progress was made in investigating the functional implications and disease-relevance of DNA methylation and non-coding RNAs in the context of $\mathrm{AD}$ and tauopathies, we will mainly focus on the discussion of these epigenetic mechanisms. However, we will shortly introduce all aforementioned epigenetic signatures.

Histone Variants and modifications: The repeated basic unit of chromatin the nucleosome - is composed of DNA wrapped around histone octamers, which are formed of the highly conserved H2A, H2B, H3, and $\mathrm{H} 4$ histone proteins. In addition to replication-dependent canonical histones, particular histone variants exist, which either display significant structural dissimilarities (e.g., macroH2A, the centromere-specific protein CENP-A), or minor sequence differences (e.g., the canonical H3.1 and H3.2, and the variant H3.3). Histone variants display different cell-type specific expression levels [42], and undergo particular posttranslational histone modifications [43]. Dependent on the incorporated variant, the site of insertion in the genome as well as the variant-specific posttranslational modifications, histone variants can differentially affect gene transcription.

Posttranslational histone modifications come in different flavors, such as acetylation, methylation, phosphorylation, SUMOylation and ADP-ribosylation [44], and occur mostly at the N-terminal tails of the histone proteins. They represent dynamic and reversible modifications differently influencing gene transcription. The regulation of these post-translational histone modifications depends on antagonistic sets of enzyme complexes that either attach (writers) or remove (erasers) the respective chemical groups. One of the most intensively studied histone modifications is the acetylation of lysine residues. While adding of acetyl groups, catalyzed by acetyl transferases (HATs), is associated with transcriptional activation, the erasure of acetyl groups by histone deacetylases (HDACs) leads to condensed chromatin [45]. Histone methylation likewise influences the accessibility of the DNA, which is associated either with transcriptional repression or activation. This depends on the site and the degree of methylation, being bound by particular readers, which mediate the transcriptional repression or activation by interacting with respective regulatory proteins or complexes. While H3K4-trimethylation (me3) leads to open 
chromatin, H3K27me3 causes chromatin condensation associated with gene repression [46].

DNA methylation: In addition to modification of histone proteins, the DNA itself can be chemically modified by DNA methylation, occurring mostly on cytosines, but also on adenines [47]. DNA methylation is catalyzed by DNA methyltransferases (DNMTs), with DNMT1 and DNMT3A being predominantly expressed in the adult brain [48]. DNA methylation at enhancer and promoter sites is associated with transcriptional regulation. Further, DNA methylation can occur in gene bodies and intergenic regions, being involved in repression of repetitive elements, alternative splicing and alternative promoter choice $[49,50]$.

DNA methylation affects transcription by diverse mechanisms. For example, methylation of transcription factor binding motifs can physically impede transcription factor binding, resulting in suppression of transcription. In addition, methyl-CpG-binding domain proteins (MBDs) interact with methylated DNA, which then recruit other chromatin and nucleosome remodeling factors, promoting inactive heterochromatin formation [51]. This is in line with the textbook model of repressive DNA methylation in gene promoter regions. Contrasting the accepted function of DNA methylation preventing the binding of proteins without a methyl-CpG-binding domain (MBD), different studies reported that DNA methylation signatures can also serve as binding motifs for specific transcription factors without a methyl binding domain [52]. In silico studies revealed an increasing pool of transcription factors predicted to bind methylated DNA sequences, and emerging scenarios propose that DNA methylation signatures could create new binding motifs for particular transcription factors. Likewise, certain transcription factors might even recognize different sequences, dependent on whether being methylated or not [53].

Alike the modification of histone proteins, DNA methylation is a dynamic process. In addition to passive DNA demethylation in dividing progenitors, Teneleven translocation (TET) family enzyme-dependent mechanisms initiate active DNA demethylation, also in non-dividing cells such as neurons [54]. Through TET-mediated oxidation of 5-methylcytosine $(5 \mathrm{mc})$ to 5-hydroxymethylcytosine (5hmc) and iterative oxidation forms, active reversion to cytosine can be achieved by thymine DNA glycosylase (TDG)-mediated base excision repair [55,56], which is also observed in neurons $[57,58]$.

Non-coding RNAs: Non-coding RNAs are distinguished in small and long non-coding RNAs (scnRNAs and lncRNAs, respectively), which differ in size, biogenesis, and function. The sncRNAs, including miRNAs, siRNAs and piRNAs, mainly act on posttranscriptional regulation in the cytoplasm [59]. In contrast, the functional spectrum of lncRNAs is tremendously diverse, modulating transcription and post-transcriptional events in the nucleus, and further acting on translation, e.g. by acting as a sponge for, or precursors of miRNAs [54].

Crosstalk between epigenetic mechanisms: The different mechanisms concertedly modulate chromatin structure and gene expression involving an intensive crosstalk. For example, particular histone modifications predispose for the establishment of DNA methylation marks and vice versa $[51,60]$. Moreover, DNMTs influence histone modifications by regulating the transcription of genes encoding for enzymes of histone modifying complexes as well as by interacting 
e.g. with the PRC2 at protein level $[61,62]$. Moreover, lncRNAs were reported to recruit or evict the binding of DNMTs and histone modifying complexes [59,63], mediating target specificity. Hence, a complex interplay between different epigenomic remodelers exists, which concertedly orchestrate transcriptional and posttranscriptional regulation, coordinating diverse physiological processes in health and disease.

\section{Age-dependent changes of DNA methylation signatures and the relevance for AD and tauopathies}

Aberrant gene expression, genomic instability, and the loss in chromatin structure are features of both aging and multifactorial or complex diseases such as AD $[64,65]$. These alterations are intimately associated to changes in the epigenome [66], and can be responsive to environmental influence [67]. As aging represents the main risk factor for $\mathrm{AD}$ and most tauopathies, it is conceivable that the epigenetic changes coming along with the aging process that affect brain function predispose for or are associated with $\mathrm{AD}$ and tauopathies. A common hallmark of both healthy aging and $\mathrm{AD} /$ tauopathies, is the decline in memory function. Changes in the gene expression of chromatin remodeling enzymes, such as DNMTs and histone modifying proteins, have been associated with alterations in synaptic plasticity, learning and memory [68-73]. Moreover, the expression or activity of epigenetic modifiers is altered in the aging brain [74]. Together, this underlines the relevance of epigenetic modifications in the context of aging and $\mathrm{AD}$, which will be discussed as follows.

The age-related decline in Dnmt3a2 expression seems to be associated with diminished cognitive abilities, as these were restored upon the rescue of decreased Dnmt3a2 levels in mice [75]. In line with the decline in DNMT expression upon aging, global hypomethylation with local sites of hypermethylation were observed in aging brains across species, affecting the expression of genes related to synapse function, cellular homeostasis but also neuronal development [76,77]. Such age-associated DNA methylation changes are proposed to contribute to transcriptional alterations of AD-related genes, possibly predisposing for the disease [78,79]. Indeed, the expression levels of key genes associated with $\mathrm{AD}$ and taupathies' pathophysiology were suggested to be regulated by DNA methylation in an age-dependent fashion. This is true e.g. for the membrane protein APP (Amyloid-Precursor Protein), concentrated in the synapses. As indicated above, mutations in $A P P$ lead to a rare genetic and early onset form of $\mathrm{AD}$, due to increased production of the amyloidogenic Amyloidbeta $(A \beta)$ protein, the main component of the plaques deposited in the brain of AD patients. The APP coding gene, which is frequently methylated, displays an age-related demethylation of cytosines in the promoter region (those at -207 to approximately -182), suggested to be linked to the $A \beta$ deposition in the aged brain $[80,81]$. In contrast, the promoter regions of the neprilysin (NEP) gene, known to inhibit AD occurrence, turned out to be highly methylated in AD brains [82]. NEP, which is a major $A \beta$-degrading enzyme in the brain fulfilling critical functions in the clearance of $A \beta$, was found down-regulated in both $A D$ and aged healthy brains [83]. The increased methylation of the NEP gene results in decreased expression, which then negatively impacts $A \beta$ clearance, potentially being causative for the elevated $A \beta$ plaque burden of the aging brain [82]. 
Moreover, age-related changes in the cytosine methylation status in a promoter region of the microtubule-related protein TAU (MAPT) gene were identified. While in the binding sites of the transcriptional activator SP1 a significant age-related increase in $5 \mathrm{mC}$ was observed in autopsy human cerebral cortex, a decrease with age of $5 \mathrm{mC}$ in the binding sites for GCF, a repressor of GCrich promoters, was revealed [81]. The authors propose that the methylation status of cytosines in the promoter region of the MAPT gene changes with age to reduce its transcriptional activity in the human cerebral cortex.

\section{Evidence for the implication of altered DNA methylation signatures in AD and tauopathies}

Similar to the aging brain, global DNA hypomethylation was reported for $\mathrm{AD}$, supported by decreased immunoreactivity for 5-methylcytosine (5-mC) in cortical neurons of postmortem AD brains compared to controls [84]. Reduced levels of $5 \mathrm{mC}$ were observed in the hippocampus, entorhinal and prefrontal cortex, as well as in the cerebellum of patients with $\mathrm{AD}$ [84-86]). In line with this, Mastroeni et al. (2010) found weak staining with antibodies directed against DNA methylation maintenance factors in hippocampal tissue of AD patients compared to normal brains. These studies are in line with findings obtained from a rare set of monozygotic twins discordant for $\mathrm{AD}$, revealing reduced levels of DNA methylation in neuronal nuclei of the AD twin in the temporal neocortex [87].

For genes such as MCF2L, ANK1, MAP2, LRRC8B, STK32C and S100B, neuronal and glia cell-type specific differential methylation dynamics associated with AD Braak stage progression were observed, and methylation changes at the key $\mathrm{AD}$ risk genes $A P P$ and $A D A M 17$ were identified in a meta-analysis [88]. Elevated DNA methylation levels in the promoter region of apolipoprotein $\mathrm{E}$ $(A P O E)$ gene were demonstrated to increase the odds of dementia and AD [89]. Genetic variation in the $A P O E$ gene is related with $\mathrm{AD}$ risk and the severity of amyloid- $\beta(\mathrm{A} \beta)$ burden, with the APOE $\varepsilon 4$ variant described to be by far the most consistent genetic risk factor $[90,91]$. The DNA methylation-dependent effect was independent of $A P O E$ genotype, suggesting that allelic variation and methylation variation in $A P O E$ may independently affect the risk of dementia [89].

DNA methylation changes leading to pathological phosphorylation of TAU: Disturbed methylation levels in promoter regions of genes related to TAU phosphorylation, which plays a critical role in tauopathies, were revealed by diverse clinical and basic research studies in the context of AD [92]. During early $\mathrm{AD}$ development, low DNA methylation levels were found in the promoter region of the GSK3 $\beta$ gene (GSK3B) from the prefrontal cortex tissue of AD patients. GSK3 $\beta$ was further found overexpressed in patients with initial AD [93]. GSK3 $\beta$ is the kinase most commonly implicated in hyperphosphorylation of the TAU protein, which is in turn believed to be a prerequisite for aggregation and formation of NFTs [94]. While at Braak stages I-II a decrease of the inactive GSK3 $\beta$ was found in the cortex from AD patients, considerable increase was observed in $\mathrm{AD}$ patients at stages V-VI, when being compared to the control subjects. It is proposed by the authors that GSK3 $\beta$ hyperactivity, and then NFTs formation, could be initiated at an early stage of the disease and turned off at final stages [93]. 
TAU hyperphosphorylation is further driven by upregulated Cdk5 expression, causing diminished long-term synaptic potentiation and culminating in impairments of spatial learning and memory. Low levels of cytosine methylation were detected in the promoter region of $C d k 5$ in the hippocampal CA1 region in a rat model with A $\beta 1$-42-induced memory deficiency [95].

Increased DNA methylation, linearly correlating with the Braak stage, was observed in the promoter region of the dual specificity phosphatase 22 gene (DUSP22) in hippocampi of $\mathrm{AD}$ patients. In line with the well-accepted transcriptionally repressive function of promoter methylation, reduced DUSP22 expression was detected at mRNA and protein level. As DUSP22 was found to inhibit the PKA-mediated TAU phosphorylation [96], its reduced expression could have direct consequence for disease progression. In addition to TAU, PKA activates the Ser133phosphorylation of the cAMP response element-binding protein (CREB). CREB activity is known to be relevant for neuronal function and synaptic plasticity, long-term memory formation and neuronal survival regulation [97]; all being compromised in AD [98]. Hence, the reduced DUSP22 expression could promote neuronal survival through elevated PKA/CREB activation. The authors propose the increase in DUSP22 promoter methylation to be a consequence of $A \beta$-induced toxicity, in the sense that cells respond with active methylation to improve their survival [96].

TAU phosphorylation can further be influenced by Tet-dependent DNA demethylation. BDNF, as a key component in the maintenance of synaptic plasticity and synaptogenesis in the hippocampus [99], is closely related to TAU hyperphosphorylation $[100,101]$. It was reported that the BDNF chromatin status and promoter accessibility is regulated by TET1 and ERK1/2 [102]. Due to this, it is assumed that TET1-dependent BDNF DNA demethylation influences TAU phosphorylation levels. Overall, these studies provide evidence for an implication of DNA methylation dependent transcriptional control of TAU phosphorylationrelated genes in AD. Most of these genes are effectors downstream of $\mathrm{A} \beta$ pathology, but upstream of TAU pathology closely related to cognitive dysfunction in patients. Thus, targeting these genes might disrupt the amyloid cascade upstream of TAU and are thus potential targets for AD treatment strategies.

Altered DNA methylation signatures as a consequence of disease pathophysiology, such as amyloid $\beta(\mathrm{A} \beta)$ burden and TAU-phosphorylation

As mentioned above for DUSP22, changes in DNA methylation could be a consequence of the altered neuronal physiology in $\mathrm{AD}$ and tauopathies, such as the accumulation of $A \beta$ peptides. Hence, altered epigenetic signatures could be a bystander of disease progression, leading to the devastating dysregulation of genes and driving the further progression of neurodegeneration in AD and other tauopathies. Furthermore, distinct mutations associated with these diseases could elicit "secondary" changes in DNA methylation pattern.

$A \beta$ peptide and TAU-phosphorylation-driven changes in the expression and localization of DNA repair related proteins: Disruption of maintenance of genomic integrity emerges to play a central role in $\mathrm{AD}$ and related pathology [103]. Early intraneuronal accumulation of $A \beta$ peptides promotes global DNA hypomethylation and through this, increased expression of genes being involved 
in DNA repair such as BRCA1, in the mouse model [104]. BRCA1 has been identified to be upregulated in response to $A \beta$ stimulation, in both cellular in vitro and in vivo mouse models, acting neuroprotectively against $A \beta$-induced DNA double-strand breaks. Hypomethylation and up-regulated expression of BRCA1 was further observed in postmortem brain samples from AD patients [105]. However, in the hippocampal CA1 region and entorhinal cortex of the AD brain, BRCA1 protein has been found mislocalized to the cytoplasm and insoluble [105]. In line with the cytosolic mislocalization, nuclear BRCA1 protein, but not of other members of Defective DNA Repair (DDR) mechanisms, were found to be reduced in AD brains [106]. The cytoplasmic BRCA1 mislocalization is proposed to represent a consequence of pTAU deposition, which is in line with the observation that brain regions without TAU pathology, namely the occipital lobe and the cerebellum, are free of cytoplasmic accumulation of BRCA1 despite decreased methylation of the respective gene. The insolubility of BRCA1 under the presence of aggregated TAU is proposed to be the reason for its dysfunction despite enhanced expression, contributing to compromised genomic integrity of neurons and hence, disease pathophysiology [105]. BRCA1 was sequestered to TAU inclusions not only in AD brains, but also in brains of patients suffering from other tauopathies (namely PiD, PSP, CBD, FTDP17/FTLD-TAU) [107,108], strengthening the role for TAU in disruption of DDR.

$A \beta$-associated changes in DNA methylation of cell cycle-related genes: In addition to compromised genomic integrity, dysregulated cell cycle control is an integral part of AD. While in a healthy neuron, abnormal cell cycle reentry leads to apoptosis, abnormal reentry in neurons of aged subjects with AD triggers a cycle of oxidative damage and mitogen production facilitating TAU hyperphosphorylation and $A \beta$ deposition, leading to full blown pathology and cognitive decline [109].

For genes promoting the activation of cell cycle reentry (i.e., via CDK5), hypomethylation was observed in $\mathrm{AD}$ or in $\mathrm{AD}$ disease paradigms [110]. In support of the hypothesis that DNA methylation changes represent a downstream effect triggered by $A ß$ plaques, the exposure of differentiated human neurons to $\mathrm{A} \beta$ results in DNA methylation abnormalities of cell-fate genes controlling neuronal differentiation and apoptosis [110].

In this context, a recent study described a potential mechanism for DNA methylation-mediated $A \beta$ peptide overproduction, which then drives $A \beta$ peptide-triggered hypomethylation of cell cycle-associated genes [111]. Li et al. (2019) [111] found that AD neurons display significant hypomethylation in the enhancer of the DSCAML1 gene that targets BACE1. BACE1 encodes the $\beta$ secretase, which cleaves amyloid precursor protein (APP) thereby acting on $A \beta$ production. Hence, the DSCAML1 enhancer hypomethylation is suggested to activate BACE1 transcription, putatively leading to the overproduction of $A \beta$ peptides, which eventually form plaques. As mentioned above, plaques are reported to occur early in AD typically preceding the spread of neurofibrillary tangles and neurodegeneration [112,113]. In addition to plaque formation, the A $\beta$ peptides are proposed to engage the pathogenic hypomethylation of enhancers affecting neurogenesis and cell cycle genes, which are suggested to be already primed for activation due to the age-related global hypomethylation [111]. Changes of DNA methylation signatures in enhancer regulatory elements are 
frequently observed in $\mathrm{AD}$ brains [114,115]. Together, this indicates that epigenetic impairment of enhancer function is implicated in AD.

The studies described so far illustrate that changes in DNA methylation signatures can be elicited in response to pathophysiological processes induced in $\mathrm{AD}$ and/or tauopathies, making the role of DNA methylation in these diseases difficult to judge. Moreover, it should be noted that changes in neuronal activity can also modify the DNA methylation landscape [116], and that altered synaptic and neuronal function is a hallmark of AD and tauopathies.

The resulting changes in DNA methylation seem to contribute to the progressive neurodegeneration by transcriptional dysregulation, whereas the detailed implication requires more intensive investigations. Dissecting the relevance of DNA methylation for AD and tauopathies is further complicated by newly arising scenarios of the biological relevance of DNA methylation. In addition, to repressive promoter methylation, intragenic DNA methylation mediates alternative splicing and promoter choice. Moreover, apart from impeding transcription factor binding, certain DNA methylation patterns seem to create new motifs for transcription factors, for which increased methylation can also result in elevated expression [117]. Hence, the transcriptional consequences of certain changes in DNA methylation need to be dissected in much more detail.

\section{Epigenetic Treatment? - The potential and limitations of DNA methylation-based therapy approaches}

As described above, hypomethylation of AD risk genes (like APP, PSEN1, and PSEN2) was described to be associated with defects in learning and memory. Increases in methyl donor S-adenosyl-L-methionine (SAM) was reported to reduce APP and PSEN1 expression by promoter hypermethylation [118,119]. In line with this, elevated levels of B12, folate and other methionine sources in the diet improve methionine bioavailability and were shown to reverse elevated expression of APP and PSEN1 [120-122].

In addition to driving hypermethylation, there is ongoing screening for DNMT inhibitors capable of modulating the methylation of AD or tauopathy risk genes. DNMT inhibitors such as azacitidine and decitabine have already been approved by the FDA for cancer treatment such as leukemia [123-125]. The use of DNA demethylating agents has also been used in some other neurodegenerative diseases, such as Friedreich's ataxia [126], which however did not provide promising results in human cells.

Finally, due to gene locus-specific changes in DNA methylation signatures, sequence-specific DNA demethylating agents, such as the oligonucleotide antisense inhibitor MG98 [127-129], seem rather be useful for future therapeutic approaches to reduce DNA methylation site-specifically than the usage of general DNMT inhibitors. Moreover, apart from site-specific hypermethylation, hypomethylation of particular genes was described to be implicated in $\mathrm{AD}^{\prime}$ and tauopathy's pathomechanisms. Hence, locus-specific editing technologies are required for altering DNA methylation, which can be achieved by clustered regulatory interspaced short palindromic repeats (CRISPR)-deactivated Cas9 (dCas9)-based editing systems that have been described as a specific and efficient method capable of manipulating site-specific DNA methylation [130]. This, in combination with improvements in cell type specific application strategies, would open the way for targeted epigenetic therapies. A major challenge for such 
epigenetic therapy is to find ways for applied molecules to pass through the blood-brain barrier, and enter specific subsets of affected cells. Moreover, as disease progression-specific alterations in DNA methylation have also been described, with some changes rather being causative or a consequence of disease pathophysiology, determining the exact stage of disease would be very beneficial. Herein, DNA methylation signatures might also help in the future, as discussed as follows.

\section{Altered DNA methylation signatures as potential biomarkers for $\mathrm{AD} /$ Tauopathies disease and disease progression?}

The use of reliable biomarkers for AD and tauopathies would be extremely beneficial for early diagnosis and monitoring disease progression, and eventually the response towards potential therapies. So, may DNA methylation signatures be useful to serve as biomarkers for $\mathrm{AD}$ and tauopathies in blood cells?

It was found that in leukocytes the intron 1 of the TREM2 gene (triggering receptor expression on myeloid cells 2) displays reduced methylation coming along with elevated expression at mRNA level in AD subjects compared to controls [131,132]. Moreover, increased levels of peripheral BDNF promoter methylation was proposed to be an epigenetic biomarker indicating the transformation of MCI to AD [133]. Similarly, increased DNA methylation levels were detected in promoter regions of the COASY and SPINT genes in plasma samples of $\mathrm{AD}$ and aMCI subjects compared to controls [134]. Methylation of the PICALM gene in blood cells was found to be related to cognitive decline of $\mathrm{AD}$ patients [135].

In general, global DNA methylation levels were found higher in peripheral blood mononuclear cells of LOAD patients compared to healthy controls, suggested to be associated with the presence of the $A P O E(4)$ allele $(\mathrm{p}=0.0043)$ and $A P O E(3)$ carriers ( $\mathrm{p}=0.05$ ) in the global population [136]). In sum, current studies indicate that monitoring global and site-specific DNA methylation in peripheral samples might be applied for individual risk screening to develop AD. However, more detailed studies and correlations are required that strengthen the use of DNA methylation as biomarkers for AD risk, diagnosis and progression, which might be expected in near future.

\section{Conclusions}

Changes in DNA methylation seem to be critically implicated in causing and/or driving the progression of $\mathrm{AD}$ and tauopathies, for which epigenetic therapy strategies hitting DNMTs and DNA methylation are discussed to be promising. However, there is still a long way to go. Firstly, locus, cell-type and disease progression-specific changes have to be clearly dissected and correlated to the transcriptional output as well as the physiological consequences. Then, targeted strategies, such as being offered by (CRISPR)-deactivated Cas9 (dCas9)based editing systems, have to be exploited and developed for site-specific manipulation of DNA methylation signatures. And finally, these manipulation systems have to be safely applicable to the brain and to specific neuronal subtypes at certain disease-progression stages. Hence, a new generation of selective probes has to be developed. In addition to potential therapeutic targets, epigenetic signatures may also help to improve diagnosis of $\mathrm{AD}$ and tauopathies, for which 


\section{epigenetic regulation likely will become an important tool in the treatment of these diseases.}

Funding: This research was funded by the Deutsche Forschungsgemeinschaft (DFG, German Research Foundation) 368482240/GRK2416DFG; DFG ZI1224/13-1 (both assigned to GZB); and the Else-Kröner-Fresenius Stiftung (2019_A41) and Köln Fortune (both assigned to HZ)

\section{References}

1. Korolev, I.O.; Symonds, L.L.; Bozoki, A.C. Predicting progression from mild cognitive impairment to Alzheimer's dementia using clinical, MRI, and plasma biomarkers via probabilistic pattern classification. PLoS One 2016, 11, doi:10.1371/journal.pone.0138866.

2. Scheltens, P.; De Strooper, B.; Kivipelto, M.; Holstege, H.; Chételat, G.; Teunissen, C.E.; Cummings, J.; van der Flier, W.M. Alzheimer's disease. Lancet 2021, 397, 1577-1590.

3. Bird, T.D. Alzheimer Disease Overview; 1993;

4. Hyman, B.T.; Phelps, C.H.; Beach, T.G.; Bigio, E.H.; Cairns, N.J.; Carrillo, M.C.; Dickson, D.W.; Duyckaerts, C.; Frosch, M.P.; Masliah, E.; et al. National Institute on Aging-Alzheimer's Association guidelines for the neuropathologic assessment of Alzheimer's disease. Alzheimer's Dement. 2012, 8 , doi:10.1016/j.jalz.2011.10.007.

5. Hammond, T.C.; Xing, X.; Wang, C.; Ma, D.; Nho, K.; Crane, P.K.; Elahi, F.; Ziegler, D.A.; Liang, G.; Cheng, Q.; et al. $\beta$-amyloid and tau drive early Alzheimer's disease decline while glucose hypometabolism drives late decline. Commun. Biol. 2020, 3, doi:10.1038/s42003-020-1079-x.

6. Gulisano, W.; Maugeri, D.; Baltrons, M.A.; Fà, M.; Amato, A.; Palmeri, A.; D’ Adamio, L.; Grassi, C.; Devanand, D.P.; Honig, L.S.; et al. Role of Amyloid- $\beta$ and Tau Proteins in Alzheimer's Disease: Confuting the Amyloid Cascade. J. Alzheimer's Dis. 2018, 64.

7. D.J., S.; J., H. The amyloid hypothesis of Alzheimer's disease at 25 years. EMBO Mol. Med. 2016, 8.

8. Roberson, E.D.; Scearce-Levie, K.; Palop, J.J.; Yan, F.; Cheng, I.H.; Wu, T.; Gerstein, H.; Yu, G.Q.; Mucke, L. Reducing endogenous tau ameliorates amyloid beta-induced deficits in an Alzheimer's disease mouse model. Science (80-. ). 2007, 316, 750-754.

9. Ittner, L.M.; Ke, Y.D.; Delerue, F.; Bi, M.; Gladbach, A.; van Eersel, J.; Wolfing, H.; Chieng, B.C.; Christie, M.J.; Napier, I.A.; et al. Dendritic function of tau mediates amyloid-beta toxicity in Alzheimer's disease mouse models. Cell 2010, 142, 387-397, doi:10.1016/j.cell.2010.06.036.

10. Zempel, H.; Luedtke, J.; Kumar, Y.; Biernat, J.; Dawson, H.; Mandelkow, E.; Mandelkow, E.M. Amyloid- $\beta$ oligomers induce synaptic damage via Taudependent microtubule severing by TTLL6 and spastin. EMBO J. 2013, 32, 2920-2937, doi:10.1038/emboj.2013.207.

11. Zempel, H.; Mandelkow, E. Mechanisms of Axonal Sorting of Tau and Influence of the Axon Initial Segment on Tau Cell Polarity. In Advances in Experimental Medicine and Biology; 2019; Vol. 1184, pp. 69-77.

12. Cho, H.; Choi, J.Y.; Hwang, M.S.; Lee, J.H.; Kim, Y.J.; Lee, H.M.; Lyoo, C.H.; Ryu, Y.H.; Lee, M.S. Tau PET in Alzheimer disease and mild cognitive impairment. Neurology 2016, 87, doi:10.1212/WNL.0000000000002892.

13. Joie, R. La; Visani, A. V.; Baker, S.L.; Brown, J.A.; Bourakova, V.; Cha, J.; Chaudhary, K.; Edwards, L.; Iaccarino, L.; Janabi, M.; et al. Prospective longitudinal atrophy in Alzheimer's disease correlates with the intensity and topography of baseline tau-PET. Sci. Transl. Med. 2020, 12, doi:10.1126/scitranslmed.aau5732.

14. Biel, D.; Brendel, M.; Rubinski, A.; Buerger, K.; Janowitz, D.; Dichgans, M.; Franzmeier, N. Tau-PET and in vivo Braak-staging as a prognostic marker in Alzheimer's disease. medRxiv 2021.

15. Bejanin, A.; Schonhaut, D.R.; La Joie, R.; Kramer, J.H.; Baker, S.L.; Sosa, N.; Ayakta, N.; Cantwell, A.; Janabi, M.; Lauriola, M.; et al. Tau pathology and neurodegeneration contribute to cognitive impairment in Alzheimer's disease. Brain 2017, 140, doi:10.1093/brain/awx243.

16. Braak, H.; Braak, E. Neuropathological stageing of Alzheimer-related changes. Acta Neuropathol 1991, 82, 239-259.

17. Braak, H.; Alafuzoff, I.; Arzberger, T.; Kretzschmar, H.; Tredici, K. Staging of Alzheimer disease-associated neurofibrillary pathology using paraffin sections and immunocytochemistry. Acta Neuropathol. 2006, 112, 389-404, doi:10.1007/s00401-006-0127-z.

18. Vogel, J.W.; Young, A.L.; Oxtoby, N.P.; Smith, R.; Ossenkoppele, R.; Strandberg, O.T.; Joie, R. La; Aksman, L.M.; Grothe, M.J.; Iturria-Medina, Y.; et al.

Characterizing the spatiotemporal variability of Alzheimer's disease pathology. medRxiv 2020.

19. Drubin, D.G. Tau protein function in living cells. J. Cell Biol. 2004, 103, 2739-2746, doi:10.1083/jcb.103.6.2739.

20. Neve, R.L.; Donlon, T.A.; Kurnit, D.M.; Harris, P.; Kosik, K.S. Identification of cDNA clones for the human microtubule-associated protein tau and chromosomal localization of the genes for tau and microtubule-associated protein 2. Mol. Brain Res. 2003, 1, 271-280, doi:10.1016/0169-328x(86)90033-1.

21. Andreadis, A. Tau splicing and the intricacies of dementia. J. Cell. Physiol. 2012, 227, 1220-1225, doi:10.1002/jcp.22842.

22. Trabzuni, D.; Wray, S.; Vandrovcova, J.; Ramasamy, A.; Walker, R.; Smith, C.; Luk, C.; Gibbs, J.R.; Dillman, A.; Hernandez, D.G.; et al. MAPT expression and splicing is differentially regulated by brain region: relation to genotype and implication for tauopathies. Hum Mol Genet 2012, 21, 4094-4103, doi:10.1093/hmg/dds238.

23. Doran, M.; Du Plessis, D.G.; Ghadiali, E.J.; Mann, D.M.A.; Pickering-Brown, S.; Larner, A.J. Familial early-onset dementia with tau intron $10+16$ mutation with clinical features similar to those of Alzheimer disease. Arch. Neurol. 2007, 64, doi:10.1001/archneur.64.10.1535.

24. Morris, H.R.; Osaki, Y.; Holton, J.; Lees, A.J.; Wood, N.W.; Revesz, T.; Quinn, N. Tau exon $10+16$ mutation FTDP-17 presenting clinically as sporadic young onset PSP. Neurology 2003, 61, doi:10.1212/01.WNL.0000072325.27824.A5.

25. Zempel, H.; Mandelkow, E. Lost after translation: Missorting of Tau protein and consequences for Alzheimer disease. Trends Neurosci. 2014, 37, 721-732, doi:10.1016/j.tins.2014.08.004.

26. Zempel, H.; Dennissen, F.J.A.; Kumar, Y.; Luedtke, J.; Biernat, J.; Mandelkow, E.M.; Mandelkow, E. Axodendritic sorting and pathological missorting of Tau are isoform-specific and determined by axon initial segment architecture. J. Biol. Chem. 2017, 292, 12192-12207, doi:10.1074/jbc.M117.784702. 
27. Bell, M.; Bachmann, S.; Klimek, J.; Langerscheidt, F.; Zempel, H. Axonal TAU sorting in SH-SY5Y-derived neurons requires the C-terminus of TAU but is independent of Ankyrin G. bioRxiv 2020, 2020.06.26.173526, doi:10.1101/2020.06.26.173526.

28. Ali, F.; Josephs, K. Rare Tauopathies. Semin. Neurol. 2019, 39, doi:10.1055/s-0039-1678584.

29. Spillantini, M.G.; Goedert, M. Tau pathology and neurodegeneration. Lancet Neurol. 2013, 12, 609-622, doi:10.1016/S1474-4422(13)70090-5.

30. Wang, Y.; Mandelkow, E. Tau in physiology and pathology. Nat. Rev. Neurosci. 2016, 17, 5-21.

31. Sultan, A.; Nesslany, F.; Violet, M.; Begard, S.; Loyens, A.; Talahari, S.; Mansuroglu, Z.; Marzin, D.; Sergeant, N.; Humez, S.; et al. Nuclear tau, a key player in neuronal DNA protection. J Biol Chem 2011, 286, 4566-4575, doi:10.1074/jbc.M110.199976.

32. Murley, A.G.; Coyle-Gilchrist, I.; Rouse, M.A.; Simon Jones, P.; Li, W.; Wiggins, J.; Lansdall, C.; Rodríguez, P.V.; Wilcox, A.; Tsvetanov, K.A.; et al.

Redefining the multidimensional clinical phenotypes of frontotemporal lobar degeneration syndromes. Brain 2020, 143, doi:10.1093/brain/awaa097.

33. Bellenguez, C.; Grenier-Boley, B.; Lambert, J.C. Genetics of Alzheimer's disease: where we are, and where we are going. Curr. Opin. Neurobiol. $2020,61$.

34. Bellenguez, C.; Küçükali, F.; Jansen, I.; Andrade, V.; Morenau-Grau, S.; Amin, N.; Grenier-Boley, B.; Boland, A.; Kleineidam, L.; Holmans, P.; et al. Large meta-analysis of genome-wide association studies expands knowledge of the genetic etiology of Alzheimer's disease and highlights potential translational opportunities. medRxiv 2020.

35. Schwartzentruber, J.; Cooper, S.; Liu, J.Z.; Barrio-Hernandez, I.; Bello, E.; Kumasaka, N.; Young, A.M.H.; Franklin, R.J.M.; Johnson, T.; Estrada, K.; et al. Genome-wide meta-analysis, fine-mapping and integrative prioritization implicate new Alzheimer's disease risk genes. Nat. Genet. 2021, 53, doi:10.1038/s41588-02000776-w.

36. Tacik, P.; Sanchez-Contreras, M.; Rademakers, R.; Dickson, D.W.; Wszolek, Z.K. Genetic disorders with tau pathology: A review of the literature and report of two patients with tauopathy and positive family histories. In Proceedings of the Neurodegenerative Diseases; 2016; Vol. 16, pp. 12-21.

37. Tacik, P.; Wszolek, Z.; SanchezContreras, M.; Rademakers, R.; Dickson, D. Literature review of genetic disorders with tau pathology. Neurology 2016.

38. Mulroy, E.; Jaunmuktane, Z.; Balint, B.; Erro, R.; Latorre, A.; Bhatia, K.P. Some New and Unexpected Tauopathies in Movement Disorders. Mov. Disord.

Clin. Pract. 2020, 7, 616-626, doi:10.1002/mdc3.12995

39. Darwich, N.F.; Phan, J.M.; Kim, B.; Suh, E.; Papatriantafyllou, J.D.; Changolkar, L.; Nguyen, A.T.; O’Rourke, C.M.; He, Z.; Porta, S.; et al. Autosomal dominant VCP hypomorph mutation impairs disaggregation of PHF-tau. Science (80-. ). 2020, 370, doi:10.1126/science.aay8826.

40. Wen, Y.; Zhou, Y.; Jiao, B.; Shen, L. Genetics of progressive supranuclear palsy: A review. J. Parkinsons. Dis. $2021,11$.

41. Huin, V.; Deramecourt, V.; Caparros-Lefebvre, D.; Maurage, C.A.; Duyckaerts, C.; Kovari, E.; Pasquier, F.; Buée-Scherrer, V.; Labreuche, J.; Behal, H.; et al. The MAPT gene is differentially methylated in the progressive supranuclear palsy brain. Mov. Disord. 2016, 31, doi:10.1002/mds.26820.

42. Rogakou, E.P.; Sekeri-Pataryas, K.E. Histone variants of H2A and H3 families are regulated during in vitro aging in the same manner as during differentiation. Exp. Gerontol. 1999, 34, doi:10.1016/S0531-5565(99)00046-7.

43. Yadav, T.; Quivy, J.P.; Almouzni, G. Chromatin plasticity: A versatile landscape that underlies cell fate and identity. Science (80-. ). $2018,361$.

44. Taylor, B.C.; Young, N.L. Combinations of histone post-Translational modifications. Biochem. J. 2021, 478.

45. Brownell, J.E.; Zhou, J.; Ranalli, T.; Kobayashi, R.; Edmondson, D.G.; Roth, S.Y.; Allis, C.D. Tetrahymena histone acetyltransferase A: A homolog to yeast Gcn5p linking histone acetylation to gene activation. Cell 1996, 84, doi:10.1016/S0092-8674(00)81063-6.

46. Lachner, M.; O'Sullivan, R.J.; Jenuwein, T. An epigenetic road map for histone lysine methylation. J. Cell Sci. $2003,116$.

47. Greenberg, M.V.C. Get Out and Stay Out: New Insights Into DNA Methylation Reprogramming in Mammals. Front. Cell Dev. Biol. 2021, 8.

48. Bayraktar, G.; Kreutz, M.R. Neuronal DNA Methyltransferases: Epigenetic Mediators between Synaptic Activity and Gene Expression? Neuroscientist 2018,

24.

49. Smith, Z.D.; Meissner, A. DNA methylation: Roles in mammalian development. Nat. Rev. Genet. 2013, 14

50. $\quad$ Maunakea, A.K.; Nagarajan, R.P.; Bilenky, M.; Ballinger, T.J.; Dsouza, C.; Fouse, S.D.; Johnson, B.E.; Hong, C.; Nielsen, C.; Zhao, Y.; et al. Conserved role of intragenic DNA methylation in regulating alternative promoters. Nature 2010, 466, doi:10.1038/nature09165.

51. Du, J.; Johnson, L.M.; Jacobsen, S.E.; Patel, D.J. DNA methylation pathways and their crosstalk with histone methylation. Nat. Rev. Mol. Cell Biol. 2015, 16, doi:10.1038/nrm4043

52. Hudson, N.O.; Whitby, F.G.; Buck-Koehntop, B.A. Structural insights into methylated DNA recognition by the C-terminal zinc fingers of the DNA reader protein ZBTB38. J. Biol. Chem. 2018, 293, doi:10.1074/jbc.RA118.005147.

53. Zhu, H.; Wang, G.; Qian, J. Transcription factors as readers and effectors of DNA methylation. Nat. Rev. Genet. 2016, 17, doi:10.1038/nrg.2016.83.

54. Wu, X.; Zhang, Y. TET-mediated active DNA demethylation: Mechanism, function and beyond. Nat. Rev. Genet. 2017, 18.

55. Ito, S.; Shen, L.; Dai, Q.; Wu, S.C.; Collins, L.B.; Swenberg, J.A.; He, C.; Zhang, Y. Tet proteins can convert 5-methylcytosine to 5-formylcytosine and 5carboxylcytosine. Science (80-. ). 2011, 333, doi:10.1126/science.1210597.

56. Kohli, R.M.; Zhang, Y. TET enzymes, TDG and the dynamics of DNA demethylation. Nature 2013, 502.

57. Kaas, G.A.; Zhong, C.; Eason, D.E.; Ross, D.L.; Vachhani, R. V.; Ming, G. li; King, J.R.; Song, H.; Sweatt, J.D. TET1 controls CNS 5-Methylcytosine Hydroxylation, active DNA demethylation, gene transcription, and memory formation. Neuron 2013, 79, doi:10.1016/j.neuron.2013.08.032.

58. Li, M.; Guo, S.; Xu, Y.; Meng, Q.; Li, G.; Yang, X. Glycine betaine-mediated potentiation of HSP gene expression involves calcium signaling pathways in tobacco exposed to $\mathrm{NaCl}$ stress. Physiol Plant 2014, 150, 63-75, doi:10.1111/ppl.12067.

59. Zimmer-Bensch, G. Emerging Roles of Long Non-Coding RNAs as Drivers of Brain Evolution. Cells 2019, 8.

60. Hashimshony, T.; Zhang, J.; Keshet, I.; Bustin, M.; Cedar, H. The role of DNA methylation in setting up chromatin structure during development. Nat. Genet. 2003, 34, doi:10.1038/ng1158.

61. Symmank, J.; Zimmer, G. Regulation of neuronal survival by DNA methyltransferases. Neural Regen. Res. $2017,12$.

62. Symmank, J.; Bayer, C.; Schmidt, C.; Hahn, A.; Pensold, D.; Zimmer-Bensch, G. DNMT1 modulates interneuron morphology by regulating Pak6 expression through crosstalk with histone modifications. Epigenetics 2018, 13, doi:10.1080/15592294.2018.1475980. 
63. Marchese, F.P.; Raimondi, I.; Huarte, M. The multidimensional mechanisms of long noncoding RNA function. Genome Biol. $2017,18$.

64. Spiegel, A.M.; Sewal, A.S.; Rapp, P.R. Epigenetic contributions to cognitive aging: Disentangling mindspan and lifespan. Learn. Mem. $2014,21$.

65. López-otín, C.; Blasco, M.A.; Partridge, L.; Serrano, M.; Kroemer, G. The Hallmarks of Aging Longevity. Cell $2013,153$.

66. Rowbotham, D.A. Epigenetic Changes in Aging and Age-related Disease. J. Aging Sci. 2015, 03, doi:10.4172/2329-8847.1000130.

67. Grant, W.B.; Campbell, A.; Itzhaki, R.F.; Savory, J. The significance of environmental factors in the etiology of Alzheimer's disease. J. Alzheimer's Dis. 2002, 4.

68. Levenson, J.M.; Roth, T.L.; Lubin, F.D.; Miller, C.A.; Huang, I.C.; Desai, P.; Malone, L.M.; Sweatt, J.D. Evidence that DNA (cytosine-5) methyltransferase regulates synaptic plasticity in the hippocampus. J. Biol. Chem. 2006, 281, doi:10.1074/jbc.M511767200.

69. Morris, M.J.; Monteggia, L.M. Role of DNA methylation and the DNA methyltransferases in learning and memory. Dialogues Clin. Neurosci. 2014, 16, doi:10.31887/dens.2014.16.3/mmorris.

70. Laplant, Q.; Vialou, V.; Covington, H.E.; Dumitriu, D.; Feng, J.; Warren, B.L.; Maze, I.; Dietz, D.M.; Watts, E.L.; Iñiguez, S.D.; et al. Dnmt3a regulates emotional behavior and spine plasticity in the nucleus accumbens. Nat. Neurosci. 2010, 13, doi:10.1038/nn.2619.

71. Xu, S.; Wilf, R.; Menon, T.; Panikker, P.; Sarthi, J.; Elefant, F. Epigenetic control of learning and memory in drosophila by Tip60 HAT action. Genetics 2014, 198, doi:10.1534/genetics.114.171660.

72. Guan, J.S.; Haggarty, S.J.; Giacometti, E.; Dannenberg, J.H.; Joseph, N.; Gao, J.; Nieland, T.J.F.; Zhou, Y.; Wang, X.; Mazitschek, R.; et al. HDAC2 negatively regulates memory formation and synaptic plasticity. Nature 2009, 459, doi:10.1038/nature07925.

73. McQuown, S.C.; Barrett, R.M.; Matheos, D.P.; Post, R.J.; Rogge, G.A.; Alenghat, T.; Mullican, S.E.; Jones, S.; Rusche, J.R.; Lazar, M.A.; et al. HDAC3 is a critical negative regulator of long-term memory formation. J. Neurosci. 2011, 31, doi:10.1523/JNEUROSCI.5052-10.2011.

74. Cui, D.; Xu, X. Dna methyltransferases, dna methylation, and age-associated cognitive function. Int. J. Mol. Sci. 2018, 19.

75. Oliveira, A.M.M.; Hemstedt, T.J.; Bading, H. Rescue of aging-associated decline in Dnmt3a2 expression restores cognitive abilities. Nat. Neurosci. 2012, 15, doi:10.1038/nn.3151.

76. Johnson, A.A.; Akman, K.; Calimport, S.R.G.; Wuttke, D.; Stolzing, A.; De Magalhães, J.P. The role of DNA methylation in aging, rejuvenation, and agerelated disease. Rejuvenation Res. 2012, 15, doi:10.1089/rej.2012.1324.

77. Hahn, A.; Pensold, D.; Bayer, C.; Tittelmeier, J.; González-Bermúdez, L.; Marx-Blümel, L.; Linde, J.; Groß, J.; Salinas-Riester, G.; Lingner, T.; et al. DNA Methyltransferase 1 (DNMT1) Function Is Implicated in the Age-Related Loss of Cortical Interneurons. Front. Cell Dev. Biol. 2020, 8, doi:10.3389/fcell.2020.00639.

78. McKinney, B.C.; Lin, C.W.; Rahman, T.; Oh, H.; Lewis, D.A.; Tseng, G.; Sibille, E. DNA methylation in the human frontal cortex reveals a putative mechanism for age-by-disease interactions. Transl. Psychiatry 2019, 9, doi:10.1038/s41398-019-0372-2.

79. Salameh, Y.; Bejaoui, Y.; El Hajj, N. DNA Methylation Biomarkers in Aging and Age-Related Diseases. Front. Genet. 2020, 11.

80. Tohgi, H.; Utsugisawa, K.; Nagane, Y.; Yoshimura, M.; Genda, Y.; Ukitsu, M. Reduction with age in methylcytosine in the promoter region -224 -101 of the amyloid precursor protein gene in autopsy human cortex. Mol. Brain Res. 1999, 70, doi:10.1016/S0169-328X(99)00163-1.

81. Tohgi, H.; Utsugisawa, K.; Nagane, Y.; Yoshimura, M.; Ukitsu, M.; Genda, Y. The methylation status of cytosines in a $\tau$ gene promoter region alters with age to downregulate transcriptional activity in human cerebral cortex. Neurosci. Lett. 1999, 275, doi:10.1016/S0304-3940(99)00731-4.

82. Nagata, K.; Mano, T.; Murayama, S.; Saido, T.C.; Iwata, A. DNA methylation level of the neprilysin promoter in Alzheimer's disease brains. Neurosci. Lett. 2018, 670, doi:10.1016/j.neulet.2018.01.003.

83. Hellström-Lindahl, E.; Ravid, R.; Nordberg, A. Age-dependent decline of neprilysin in Alzheimer's disease and normal brain: Inverse correlation with A $\beta$ levels. Neurobiol. Aging 2008, 29, doi:10.1016/j.neurobiolaging.2006.10.010.

84. Mastroeni, D.; Grover, A.; Delvaux, E.; Whiteside, C.; Coleman, P.D.; Rogers, J. Epigenetic changes in Alzheimer's disease: Decrements in DNA methylation. Neurobiol. Aging 2010, 31, doi:10.1016/j.neurobiolaging.2008.12.005.

85. Chouliaras, L.; Mastroeni, D.; Delvaux, E.; Grover, A.; Kenis, G.; Hof, P.R.; Steinbusch, H.W.M.; Coleman, P.D.; Rutten, B.P.F.; van den Hove, D.L.A. Consistent decrease in global DNA methylation and hydroxymethylation in the hippocampus of Alzheimer's disease patients. Neurobiol. Aging 2013, 34, doi:10.1016/j.neurobiolaging.2013.02.021.

86. Pellegrini, C.; Pirazzini, C.; Sala, C.; Sambati, L.; Yusipov, I.; Kalyakulina, A.; Ravaioli, F.; Kwiatkowska, K.M.; Durso, D.F.; Ivanchenko, M.; et al. A MetaAnalysis of Brain DNA Methylation Across Sex, Age, and Alzheimer's Disease Points for Accelerated Epigenetic Aging in Neurodegeneration. Front. Aging Neurosci. $2021,13$.

87. Mastroeni, D.; McKee, A.; Grover, A.; Rogers, J.; Coleman, P.D. Epigenetic differences in cortical neurons from a pair of monozygotic twins discordant for Alzheimer's disease. PLoS One 2009, 4, doi:10.1371/journal.pone.0006617.

88. Gasparoni, G.; Bultmann, S.; Lutsik, P.; Kraus, T.F.J.; Sordon, S.; Vlcek, J.; Dietinger, V.; Steinmaurer, M.; Haider, M.; Mulholland, C.B.; et al. DNA methylation analysis on purified neurons and glia dissects age and Alzheimer's disease-specific changes in the human cortex. Epigenetics and Chromatin 2018, 11, doi:10.1186/s13072-018-0211-3.

89. Foraker, J.; Millard, S.P.; Leong, L.; Thomson, Z.; Chen, S.; Keene, C.D.; Bekris, L.M.; Yu, C.E.; Fischer, A. The APOE Gene is Differentially Methylated in Alzheimer's Disease. J. Alzheimer's Dis. 2015, 48, doi:10.3233/JAD-143060.

90. Bertram, L.; Lill, C.M.; Tanzi, R.E. The genetics of alzheimer disease: Back to the future. Neuron $2010,68$.

91. Lambert, J.C.; Ibrahim-Verbaas, C.A.; Harold, D.; Naj, A.C.; Sims, R.; Bellenguez, C.; Jun, G.; DeStefano, A.L.; Bis, J.C.; Beecham, G.W.; et al. Meta-analysis of 74,046 individuals identifies 11 new susceptibility loci for Alzheimer's disease. Nat. Genet. 2013, 45, doi:10.1038/ng.2802.

92. Yu, C.C.; Jiang, T.; Yang, A.F.; Du, Y.J.; Wu, M.; Kong, L.H. Epigenetic modulation on tau phosphorylation in Alzheimer's disease. Neural Plast. 2019, 2019. 93. Nicolia, V.; Ciraci, V.; Cavallaro, R.A.; Ferrer, I.; Scarpa, S.; Fuso, A. GSK3 $\beta 5^{\prime}$-flanking DNA Methylation and Expression in Alzheimer's Disease Patients. Curr. Alzheimer Res. 2017, 14, doi:10.2174/1567205014666170203153325.

94. Sayas, C.L.; Ávila, J. GSK-3 and Tau: A Key Duet in Alzheimer's Disease. Cells 2021, 10. 
95. Li, L.; Zhang, C.; Zi, X.; Tu, Q.; Guo, K. Epigenetic modulation of Cdk5 contributes to memory deficiency induced by amyloid fibrils. Exp. Brain Res. 2015, 233, doi:10.1007/s00221-014-4100-0.

96. Sanchez-Mut, J. V; Aso, E.; Heyn, H.; Matsuda, T.; Bock, C.; Ferrer, I.; Esteller, M. Promoter hypermethylation of the phosphatase DUSP22 mediates PKAdependent TAU phosphorylation and CREB activation in Alzheimer's disease. Hippocampus 2014, doi:10.1002/hipo.22245.

97. Lonze, B.E.; Riccio, A.; Cohen, S.; Ginty, D.D. Apoptosis, axonal growth defects, and degeneration of peripheral neurons in mice lacking CREB. Neuron 2002, 34, doi:10.1016/S0896-6273(02)00686-4.

98. Querfurth, H.W.; LaFerla, F.M. Alzheimer's disease: mechanism of disease. N. Engl. J. Med. 2010, doi:10.1016/B978-0-12-803699-0.00045-1.

99. Song, J.H.; Yu, J.T.; Tan, L. Brain-Derived Neurotrophic Factor in Alzheimer's Disease: Risk, Mechanisms, and Therapy. Mol. Neurobiol. 2015, 52.

100. Tanila, H. The role of BDNF in Alzheimer's disease. Neurobiol. Dis. 2017, 97.

101. Xu, A.H.; Yang, Y.; Sun, Y.X.; Zhang, C.D. Exogenous brain-derived neurotrophic factor attenuates cognitive impairment induced by okadaic acid in a rat model of Alzheimer's disease. Neural Regen. Res. 2018, 13, doi:10.4103/1673-5374.241471.

102. Ambigapathyy, G.; Zhengy, Z.; Keifer, J. Regulation of BDNF chromatin status and promoter accessibility in a neural correlate of associative learning. Epigenetics 2015, 10, doi:10.1080/15592294.2015.1090072.

103. Hou, Y.; Song, H.; Croteau, D.L.; Akbari, M.; Bohr, V.A. Genome instability in Alzheimer disease. Mech. Ageing Dev. 2017, 161,

doi:10.1016/j.mad.2016.04.005.

104. Do Carmo, S.; Hanzel, C.E.; Jacobs, M.L.; MacHnes, Z.; Iulita, M.F.; Yang, J.; Yu, L.; Ducatenzeiler, A.; Danik, M.; Breuillaud, L.S.; et al. Rescue of Early bace1 and Global DNA Demethylation by S-Adenosylmethionine Reduces Amyloid Pathology and Improves Cognition in an Alzheimer's Model. Sci. Rep. 2016, 6, doi:10.1038/srep34051.

105. Mano, T.; Nagata, K.; Nonaka, T.; Tarutani, A.; Imamura, T.; Hashimoto, T.; Bannai, T.; Koshi-Mano, K.; Tsuchida, T.; Ohtomo, R.; et al. Neuron-specific methylome analysis reveals epigenetic regulation and tau-related dysfunction of BRCA1 in Alzheimer's disease. Proc. Natl. Acad. Sci. U. S. A. 2017, 114, doi:10.1073/pnas.1707151114.

106. Suberbielle, E.; Djukic, B.; Evans, M.; Kim, D.H.; Taneja, P.; Wang, X.; Finucane, M.; Knox, J.; Ho, K.; Devidze, N.; et al. DNA repair factor BRCA1 depletion occurs in Alzheimer brains and impairs cognitive function in mice. Nat. Commun. 2015, 6, doi:10.1038/ncomms9897.

107. Nakamura, M.; Kaneko, S.; Dickson, D.W.; Kusaka, H. Aberrant accumulation of BRCA1 in Alzheimer disease and other tauopathies. J. Neuropathol. Exp. Neurol. 2020, 79, doi:10.1093/jnen/nlz107.

108. Kurihara, M.; Mano, T.; Saito, Y.; Murayama, S.; Toda, T.; Iwata, A. Colocalization of BRCA1 with Tau aggregates in human tauopathies. Brain Sci. 2020, 10, doi:10.3390/brainsci10010007.

109. Moh, C.; Kubiak, J.Z.; Bajic, V.P.; Zhu, X.; Smith, M.A.; Lee, H.G. Cell cycle deregulation in the neurons of Alzheimer's disease. Results Probl. Cell Differ. 2011, 53, doi:10.1007/978-3-642-19065-0_23.

110. Taher, N.; McKenzie, C.; Garrett, R.; Baker, M.; Fox, N.; Isaacs, G.D. Amyloid- $\beta$ alters the DNA methylation status of cell-fate genes in an Alzheimer's disease model. J. Alzheimer's Dis. 2014, 38, doi:10.3233/JAD-131061.

111. Li, P.; Marshall, L.; Oh, G.; Jakubowski, J.L.; Groot, D.; He, Y.; Wang, T.; Petronis, A.; Labrie, V. Epigenetic dysregulation of enhancers in neurons is associated with Alzheimer's disease pathology and cognitive symptoms. Nat. Commun. 2019, 10, doi:10.1038/s41467-019-10101-7.

112. Khan, U.A.; Liu, L.; Provenzano, F.A.; Berman, D.E.; Profaci, C.P.; Sloan, R.; Mayeux, R.; Duff, K.E.; Small, S.A. Molecular drivers and cortical spread of lateral entorhinal cortex dysfunction in preclinical Alzheimer's disease. Nat. Neurosci. 2014, 17, doi:10.1038/nn.3606.

113. Jack, C.R.; Knopman, D.S.; Jagust, W.J.; Shaw, L.M.; Aisen, P.S.; Weiner, M.W.; Petersen, R.C.; Trojanowski, J.Q. Hypothetical model of dynamic biomarkers of the Alzheimer's pathological cascade. Lancet Neurol. 2010, 9.

114. De Jager, P.L.; Srivastava, G.; Lunnon, K.; Burgess, J.; Schalkwyk, L.C.; Yu, L.; Eaton, M.L.; Keenan, B.T.; Ernst, J.; McCabe, C.; et al. Alzheimer's disease: Early alterations in brain DNA methylation at ANK1, BIN1, RHBDF2 and other loci. Nat. Neurosci. 2014, 17, doi:10.1038/nn.3786.

115. Watson, C.T.; Roussos, P.; Garg, P.; Ho, D.J.; Azam, N.; Katsel, P.L.; Haroutunian, V.; Sharp, A.J. Genome-wide12 DNA methylation profiling in the superior temporal gyrus reveals epigenetic signatures associated with Alzheimer's disease. Genome Med. 2016, 8, doi:10.1186/s13073-015-0258-8.

116. Guo, J.U.; Ma, D.K.; Mo, H.; Ball, M.P.; Jang, M.H.; Bonaguidi, M.A.; Balazer, J.A.; Eaves, H.L.; Xie, B.; Ford, E.; et al. Neuronal activity modifies the DNA methylation landscape in the adult brain. Nat. Neurosci. 2011, 14, doi:10.1038/nn.2900.

117. Héberlé, É.; Bardet, A.F. Sensitivity of transcription factors to DNA methylation. Essays Biochem. $2019,63$.

118. Scarpa, S.; Cavallaro, R.A.; D'Anselmi, F.; Fuso, A. Gene silencing through methylation: An epigenetic intervention on Alzheimer disease. J. Alzheimer's Dis.

$2006,9$.

119. Fuso, A.; Seminara, L.; Cavallaro, R.A.; D’Anselmi, F.; Scarpa, S. S-adenosylmethionine/homocysteine cycle alterations modify DNA methylation status with consequent deregulation of PS1 and BACE and beta-amyloid production. Mol. Cell. Neurosci. 2005, 28, doi:10.1016/j.mcn.2004.09.007.

120. Chan, A.; Shea, T.B. Effects of dietary supplementation with N-acetyl cysteine, acetyl-L-carnitine and S-adenosyl methionine on cognitive performance and aggression in normal mice and mice expressing human ApoE4 (Neuromolecular Medicine DOI: 10.1007/s12017-007-8005-y). NeuroMolecular Med. 2008, 10.

121. Fuso, A. The "golden age" of DNA methylation in neurodegenerative diseases. In Proceedings of the Clinical Chemistry and Laboratory Medicine; 2013;

Vol. 51.

122. Fuso, A.; Scarpa, S. One-carbon metabolism and Alzheimer's disease: Is it all a methylation matter? Neurobiol. Aging $2011,32$.

123. Momparler, R.L.; Momparler, L.F.; Samson, J. Comparison of the antileukemic activity of 5-aza-2'-deoxycytidine, 1- $\beta$-d-arabinofuranosylcytosine and 5azacytidine against L1210 leukemia. Leuk. Res. 1984, 8.

124. Issa, J.P.J.; Garcia-Manero, G.; Giles, F.J.; Mannari, R.; Thomas, D.; Faderl, S.; Bayar, E.; Lyons, J.; Rosenfeld, C.S.; Cortes, J.; et al. Phase 1 study of low-dose prolonged exposure schedules of the hypomethylating agent 5-aza-2'-deoxycytidine (decitabine) in hematopoietic malignancies. Blood 2004, 103, doi:10.1182/blood2003-03-0687. 
125. Lübbert, M.; Daskalakis, M.; Sander, P.N.; Kündgen, A. Azanucleoside DNA Methyltransferase inhibitor drugs: Update on clinical applications in Myelodysplastic syndromes and acute myeloid leukemia. In Proceedings of the Epigenetics and Human Health; 2016.

126. Sandi, C.; Sandi, M.; Virmouni, S.A.; Al-Mahdawi, S.; Pook, M.A. Epigenetic-based therapies for Friedreich ataxia. Front. Genet. 2014, 5.

127. Plummer, R.; Vidal, L.; Griffin, M.; Lesley, M.; De Bono, J.; Coulthard, S.; Sludden, J.; Siu, L.L.; Chen, E.X.; Oza, A.M.; et al. Phase I study of MG98, an oligonucleotide antisense inhibitor of human DNA methyltransferase 1, given as a 7-day infusion in patients with advanced solid tumors. Clin. Cancer Res. 2009, 15, doi:10.1158/1078-0432.CCR-08-2859.

128. Winquist, E.; Knox, J.; Ayoub, J.P.; Wood, L.; Wainman, N.; Reid, G.K.; Pearce, L.; Shah, A.; Eisenhauer, E. Phase II trial of DNA methyltransferase 1 inhibition with the antisense oligonucleotide MG98 in patients with metastatic renal carcinoma: A National Cancer Institute of Canada Clinical Trials Group investigational new drug study. Invest. New Drugs 2006, 24, doi:10.1007/s10637-006-5938-1.

129. Stewart, D.J.; Donehower, R.C.; Eisenhauer, E.A.; Wainman, N.; Shah, A.K.; Bonfils, C.; MacLeod, A.R.; Besterman, J.M.; Reid, G.K. A phase I pharmacokinetic and pharmacodynamic study of the DNA methyltransferase 1 inhibitor MG98 administered twice weekly. Ann. Oncol. 2003, 14, doi:10.1093/annonc/mdg216.

130. Urbano, A.; Smith, J.; Weeks, R.J.; Chatterjee, A. Gene-specific targeting of DNA methylation in the mammalian genome. Cancers (Basel). $2019,11$. 131. Ozaki, Y.; Yoshino, Y.; Yamazaki, K.; Sao, T.; Mori, Y.; Ochi, S.; Yoshida, T.; Mori, T.; Iga, J. ichi; Ueno, S. ichi DNA methylation changes at TREM2 intron 1 and TREM2 mRNA expression in patients with Alzheimer's disease. J. Psychiatr. Res. 2017, 92, doi:10.1016/j.jpsychires.2017.04.003.

132. Mori, Y.; Yoshino, Y.; Ochi, S.; Yamazaki, K.; Kawabe, K.; Abe, M.; Kitano, T.; Ozaki, Y.; Yoshida, T.; Numata, S.; et al. TREM2 mRNA expression in leukocytes is increased in Alzheimer's disease and schizophrenia. PLoS One 2015, 10, doi:10.1371/journal.pone.0136835.

133. Xie, B.; Xu, Y.; Liu, Z.; Liu, W.; Jiang, L.; Zhang, R.; Cui, D.; Zhang, Q.; Xu, S. Elevation of peripheral BDNF promoter methylation predicts conversion from amnestic mild cognitive impairment to Alzheimer's disease: a 5-year longitudinal study. J. Alzheimer's Dis. 2017, 56, doi:10.3233/JAD-160954.

134. Kobayashi, N.; Shinagawa, S.; Nagata, T.; Shimada, K.; Shibata, N.; Ohnuma, T.; Kasanuki, K.; Arai, H.; Yamada, H.; Nakayama, K.; et al. Usefulness of DNA methylation levels in COASY and SPINT1 gene promoter regions as biomarkers in diagnosis of Alzheimer's disease and Amnestic mild cognitive impairment. PLoS One 2016, 11, doi:10.1371/journal.pone.0168816.

135. Mercorio, R.; Pergoli, L.; Galimberti, D.; Favero, C.; Carugno, M.; Dalla Valle, E.; Barretta, F.; Cortini, F.; Scarpini, E.; Valentina, V.B.; et al. PICALM gene methylation in blood of Alzheimer's disease patients is associated with cognitive decline. J. Alzheimer's Dis. 2018, 65, doi:10.3233/JAD-180242.

136. Di Francesco, A.; Arosio, B.; Falconi, A.; Micioni Di Bonaventura, M.V.; Karimi, M.; Mari, D.; Casati, M.; Maccarrone, M.; D’Addario, C. Global changes in DNA methylation in Alzheimer's disease peripheral blood mononuclear cells. Brain. Behav. Immun. 2015, 45, doi:10.1016/j.bbi.2014.11.002. 